\title{
Analyzing the "Language Problem" Discourses in Hong Kong: How Official, Academic, and Media Discourses Construct and Perpetuate Dominant Models of Language, Learning, and Education
}

(In Journal of Pragmatics, 28, 1997)

Angel Mei Yi Lin

City University of Hong Kong

\begin{abstract}
In this paper, I analyze the recent official, academic, and media discourses in Hong Kong to examine how the "language problem" has been formulated and represented, and to expose and problematize the models of language, learning, and education that are being imposed by these public discourses. I seek to examine the role these discourses play in producing and perpetuating false consciousness or popular taken-for-granted notions about language and language learning among Hong Kong people. I conclude with a proposal of alternative models to the dominant ones.
\end{abstract}

[Without a legitimate name, without authority to the words...] (Confucius, circ. 500 B.C.)

The authority that underlies the performative efficacy of discourse is a percipi, a being-known, which allows a percipere to be imposed, or, more precisely, which allows the consensus concerning the meaning of the social world which grounds common sense to be imposed officially, i.e., in front of everyone and in the name of everyone... (Bourdieu, 1982/1991, p. 106)

\section{Introduction}

The language proficiency of the majority of Hong Kong students has often been formulated in the public media discourses as "declining", or in the academic and official discourses, as "falling short of the expectations of the 
community". These discourses include those found in (i) government, educational policy documents and reports, (ii) academic articles and reports, and (iii) public media, e.g., influential newspapers. The following quotation cited from recent public discourses in Hong Kong can give the reader a flavor of the tone and mood of these discourses:

\section{Example 1:}

CONSIDERING Hong Kong's long history of British rule, the general level of English language skills is curiously poor. In a number of countries never colonized or "protected" by Britain, the United States or any other English-speaking nation, English is spoken with greater fluency and by a far higher proportion of the population than it is here.

("Our second language", Editorial of South China Morning Post, April 28, 1994)

In the above excerpt from an editorial of a leading English newspaper in Hong Kong, the lack of English fluency of the majority of people in Hong Kong is contrasted with the "greater fluency" of English spoken by "a far higher proportion of population" in "any other English-speaking nation". The argument conveyed is intelligible only if one agrees to its implicit assertions that the history of British colonial rule in Hong Kong is a sufficient and reasonable ground for imposing the expectation of a high level of English language skills on a high proportion of the population colonized, no matter how culturally and linguistically distinct from English their mother tongue is, and that the existence of a British colonial government in a place automatically confers to that place an "English-speaking" status, a status that is implicitly asserted to be more legitimate than, if not similar to, that of other English-speaking nations like the United States.

To uncover the various mutually supporting and legitimizing assumptions asserted in these public discourses, let us look at more examples:

\section{Example 2:}


Hong Kong--The falling standard of English in Hong Kong is starting to pinch corporate pocketbooks.

As the territory's burgeoning service businesses boost demand for English speakers, there are signs that the English proficiency of university and secondary-school graduates entering the work force is dropping, forcing local companies to fork out large sums on remedial language training.

The growth of English-language training in the office reflects the failure of Hong Kong's education system to train students for work in the service industries that increasingly dominate the colony's economy...

"I've lived here for five years, and the problem is getting worse," says Thomas Axmacher, general manager at the Regent Hotel and chairman of the Hong Kong Hotels Association. Many of his hotels' job applicants know few English phrases other than "Yes," "No" and "I don't know," Mr. Axmacher complains. Yet high turnover among junior staff means he has few choices in choosing new hires.

(Lotte Chow, "Drop in English standard hurts Hong Kong Business", Asian Wall Street Journal Weekly, June 12, 1995, p. 1)

\section{Example 3:}

A DROP in the number of pupils passing the Use of English examination has raised concern over declining language standards.

Results, released by the Hong Kong Examinations Authority yesterday, showed only 45.9 percent of school candidates scored a grade D or above, 5.4 per cent down from last year.

The authority admitted the overall English language standard of the extra candidates was below that of the established groups, although the absolute number of students receiving grade $\mathrm{E}$ or above had increased. 
One of the biggest employers in Hong Kong, the Hongkong Bank, said it was worried that the education system did not meet the needs of the community.

("Exam results show English skills in decline", South China Morning Post, May 24, 1994)

\section{Example 4:}

...Expectations within the community are high, particularly so for English. This is not surprising, given the role English plays in higher education, the professions and the upper levels of business and government...

$\cdots$

$\cdots$

This high level of expectation largely explains the paradox whereby a spectacular increase in the numbers of Hong Kong people who feel able to understand English is simultaneously perceived as a failure on the part of the Education system to maintain standards. In English and to a lesser extent in Chinese, the gap between performance and the expectations of the community has widened as the nature of Hong Kong society changes from a manufacturing to a service industry base; i.e. as more people are required to perform language skills at higher levels. The level of demand may be expected to continue to rise so long as Hong Kong continues on its present economic and social course. The challenge for the education system is to meet that demand, and arguments whether or not standards have fallen are largely irrelevant. Merely maintaining past standards would in any case be inadequate. (Johnson, 1994, "Critical Review of Literature on Language in Education in Hong Kong", Prepared for the Education Commission Working Group on Language Proficiency, p. 2, 16)

\section{Example 5:}

...The gap between demand and supply has led to a perception that language standards are falling; but arguments about 'falling' or 'rising' standards are perhaps not very helpful. Even if language 
standards have not fallen, there is a widening gap between the needs of society and the availability of people with the skills to meet those needs. The crucial question is: how can the education system help to narrow that gap?

(Hong Kong Education Commission ${ }^{\mathrm{i}}$, Report of the Working Group on Language Proficiency, July, 1994, p. 15)

In the following sections, these and further examples of the public discourses will be analyzed to examine how the "language problem" has been formulated and represented, and to expose and problematize the implicit models of language, learning, the social actor, and education that have been assumed, asserted and legitimized in these discourses ${ }^{\text {ii }}$.

\section{Education as the Production of a Ready-Made Labor Force for Business Corporations}

A quick reading through the above examples of recent public discourses in Hong Kong is enough to give the reader a strong flavor of the implicit assumption and assertion of the legitimacy of the business corporations' demands on education.

The media discourses mainly reflect the complaints of Hong Kong employers or business interests and assert the "declining language standards" of Hong Kong students. They also assert that this decline in standards is hurting business corporations by causing them to spend more money on in-house, on-the-job language training of their employees. Interestingly, their implicit message is that the school system or education should be doing this job so that they can be provided with a ready-made labor force with little need on their part to invest in staff development (see Examples 2 and 3 above).

Some of these business interests seem to be so self-justified in their unreasonably high foreign language demands that they even complain about the lack of English resources of their junior (and generally low-paid) Chinese staff (See Example 2 above). One wonders whether any employer in Britain or the United States can 
justifiably complain about their junior staff members not having a high level of proficiency in a socioculturally and linguistically distant language such as Russian or Japanese. It seems that what the business interests in Hong Kong want is cheap but good foreign-language-speaking labor, ready-made from the school system, and ideally with little need on their part to put in any investment in staff development.

We also notice how the business interests formulate, and thus implicitly assert the legitimacy of, their own labor demands on the education system as "the needs of the community" (e.g., Example 3 above).

In comparison to the public media discourses (e.g., Example 1 above) the academic and official discourses seem to be more reasonable (e.g., Johnson, 1994; see Example 4 above). They propose the alternative theory that there is not any real decline in standards, but a rise in the demand of the business corporations for English-conversant workers, and thus a perceived drop in the supply of English-proficient school-leavers.

However, the academic and official discourses do not go beyond the "demand-and-supply" economic model of education. Implicitly, it is assumed and asserted that education should produce a ready-made labor force for business corporations, and that education should meet whatever demands they exert on the education system. In this respect, they converge with the public media discourses in assuming and asserting the legitimacy of the demands that business interests make on education by equating their demands to "the needs of the community or society" (See Examples 4 and 5 above).

A series of questions for which there seems to be little room in these public discourses might be asked. For example:

Who is "the community"? Business corporations? Foreign investors? The ruling class? The local Cantonese-speaking working-class communities?

What are the "needs" of these different groups of people?

What should be the goals of education? 
What should be the educational priorities for Hong Kong?

While I ask the above questions, I also recognize that Hong Kong has an interestingly ultra-pragmatic culture. As someone who has grown up and lived most of her life in Hong Kong, I would be the first to vote against any unrealistic educational agenda that does not equip a local Chinese school-leaver with the skills to find a job in Hong Kong. Hong Kong people are afraid of losing their "economic stability and prosperity" (a recurrent phrase in the public discourses in Hong Kong). The government, academic, and media discourses repeatedly assert that Hong Kong's economic prosperity depends on attracting foreign investors, which in turn depends on providing them with an English-conversant labor force. This saturation of consciousness by the "economic argument" has legitimized the subordination of all sociocultural and educational goals to the single goal of mastering a socially, culturally, and linguistically distant language for the majority of children in Hong Kong. Hong Kong people are left with few alternatives given this saturation of consciousness by the fear of losing their economic prosperity, a threat forcefully asserted in the economic argument. The example of Malaysia's economic decline is often quoted as an ominous warning of the unfavorable result of shifting emphasis from English to their national language in their education system after independence from Britain. What is often left unmentioned, however, is the argument that business interests have been attracted to Hong Kong, and not, say, Malaysia or Singapore, not primarily because of the availability of a large English-conversant labor force (which has never been available in Hong Kong), but because of the emergence of China in the early 1990s as a newly powerful industrializing economy and as a huge potential consumer market for foreign business interests (Pease, 1994; Ma, 1995).

In saying this, I am not suggesting that Hong Kong students and workers do not need to improve their English skills. Rather, my point is that if foreign business interests have been attracted to Hong Kong because they find it profitable to do business with China through Hong Kong ${ }^{\mathrm{iii}}$, they should at least share some of the cost and efforts in investing in the staff development in English usage required by their extra demand. 
No autonomous government in the world would take every demand of foreign business interests as their mandate. It is therefore problematic that the Hong Kong government (see Example 5 above) and prestigious academic and educational research discourses in Hong Kong (see Example 4 above) should automatically accept the business interests' demands as the mandate for the education system, and allow educational priorities to be dictated by business labor demands. In any autonomous country, any such demands will have to be weighed against other social, cultural, and educational priorities. In contrast, what is implicitly assumed, asserted and imposed in most of Hong Kong's influential public discourses is a model of education as primarily serving the needs of business interests, and education as the production of a ready-made labor force for business corporations. It is a model or an ideology that subordinates other social, cultural, and educational goals to commercialism. While this may make Hong Kong the capitalists' (perhaps especially foreign capitalists') paradise, it exerts unreasonably high foreign-language demands on the majority of Hong Kong children, who live in a non-English speaking home, and social and cultural world. The unhealthy one-sidedness of our educational discourses and practices has seldom been problematized, let alone being challenged in the public discourses in Hong Kong.

A recent official, language policy document, the Education Commission Report (ECR) No. 6, issued to the public in December, 1995, interestingly departs slightly from former language policy documents (e.g., Hong Kong Education Commission--Report of the Working Group on Language Proficiency, July, 1994) in its way of framing and introducing its economic model of education:

\section{Example 6:}

The Education Commission recognizes that the fundamental aim of our school education is to develop the potential of every child, so that our students will become independent-minded and socially-aware adults, equipped with the knowledge, skills and attitudes which help them to lead a full life as individuals and play a positive role in the life of the community. In order to achieve that, school education must equip students with the necessary language proficiency. The Commission is also 
conscious of the fact that Hong Kong's workforce will quickly lose its competitiveness in the Asia Pacific Region if nothing is done to upgrade the language proficiency of our students. There is an urgent need in Hong Kong to enhance the proficiency of Chinese (including Putonghua) and English of our young people in order to meet changing political, economic, social and cultural demands. (Education Commission Report No. 6, December, 1995, Part 1, Executive Summary, p. vi)

In previous official language policy documents, framing discourses like the first sentences in Example 6 above have never appeared. However, in this recent document, such framing discourses appear twice in the entire report, once in the opening and once in the Executive Summary. In both occurrences, the sentence explicitly stating the non-economic goals of education seems to be a pre-sequence acting as a discourse framing device. It functions to dress up an otherwise stark assertion of an economic model of education. There is no other evidence in the entire report that warrants the alternative interpretation that the sentences have any substance other than that of a discourse framing device preceding the introduction of the economic goals of education. For instance, in the entire report, there is no other mention of how the proposed language and educational policies are related to the development of students' potential, social awareness, or independent thinking, apart from the above-quoted two instances. In both instances, the reader is implicitly asked to make a logical jump: to achieve the educational goals of developing students' potential, social awareness, responsibility, and independent thinking, "school education must equip students with the necessary language proficiency" (see Example 6 above), and "enable them to handle information that is readily available here, and that means they must achieve high levels of bilingual proficiency". As we shall see in Examples 7 and 8 in Section 3 below, the words, "the necessary language proficiency", "bilingual proficiency", actually refer to proficiency in languages that do not include the mother tongue (Cantonese) of the child. From an educational perspective, it is highly doubtful that a schooling policy that aims at the development of proficiency in languages excluding the mother tongue of the child can be said to be conducive to the development of the child's potential, social awareness, or independent thinking.

\section{A Politically and Economically Defined Hierarchy of Languages}


To see what "language proficiency" refers to in the ECR No. 6, let us look at the following excerpt from the report:

\section{Example 7:}

It is clear that there is a need in Hong Kong to enhance the level of proficiency in both Chinese (including Putonghua) and English in order to satisfy the economic, political, educational and cultural demands that are being placed on individuals and the community as a whole. Specifically, the following needs have been identified as being pressing:

the need for sixth form students to have the requisite English skills to enter tertiary education institutions;

the need for school leavers and graduates to have a good command of English to enter the business, professional and service sectors;

the increasing need for people with adequate command of modern standard written Chinese for political, educational and cultural purposes; and

the increasing need for people with adequate command of Putonghua to serve in the political arena, and in trades and industries which have close ties with China.

(Education Commission Report No. 6, December, 1995, Part 1, Chapter 2: An Overview of the Present Situation and Identification of Needs, paragraph 2.20, p. 14) 
In the public discourses, as exemplified in the above excerpt, the words "language proficiency" are often used in ways that implicitly refer to proficiency in "standard Chinese and English" only, and Cantonese proficiency does not count as "language proficiency" in the majority of these discourses. The implicit assumption asserted in these discourses is that Cantonese is an unvalued "dialect", which is unfortunately everywhere in the student's environment and is "vulgarized" in the many arenas of popular entertainment culture (e.g., T.V., movies, popular magazines and comics). Its "strong presence" is seen as a cause of the students' "lack of exposure" to "Standard Chinese" and English. In these discourses, Cantonese is often portrayed as a wild and free growing weed that crowds out the student's exposure to proper language.

The majority of public discourses in Hong Kong reflect an implicitly asserted and imposed, politically and economically defined hierarchy of values on languages (e.g., see Example 7 above). Cantonese is placed close to the bottom of such a hierarchy, even though in reality it is socially and culturally the most important language for the majority of people in Hong Kong. It is after all the language of the home, playground, corridor, cafeteria, of friends and colleagues, of television, radio, movies, songs, and popular newspapers and magazines for the majority of people in Hong Kong (Luke and Richards, 1982; Fu, 1987; Lin, 1996).

However, even prestigious local sociolinguists and educationists have not been able to free themselves from some long-accepted, value-laden notions. For instance, Luke (1984) differentiates between "high" and "low" Cantonese, with "high" Cantonese converging with "Standard Chinese" and used in the "high" domains of the society, e.g., government, education, while "low" Cantonese is the Cantonese used in "low" domains such as home, entertainment, and informal social interactions, and it is more distant from "Standard Chinese". While Luke does not personally hold any pejorative views against "low" Cantonese, his use of the sociolinguistic conventional terms, "high" and "low", nevertheless can contribute to the perpetuation and legitimization of the politically and economically defined hierarchy of language values. One is not led to critically reflect on the important question of why the mother tongue, the language of social and cultural identity, and the most important everyday language of most children and adults in Hong Kong, is assigned the status of a "low" "dialect" in the majority of the public, official as well as academic discourses. To illustrate this saturation of 
consciousness by taken-for-granted notions, which implicitly impose the politically and economically defined hierarchy of linguistic values, even among prestigious and influential academics and educationists in Hong Kong, let us look at the following example taken from Johnson (1993/1994, p. 179):

\section{Example 8:}

There is a 'high' variety of Cantonese used in the education system and in government. It is influenced by and converges towards written forms of Chinese (Luke and Nancarrow, 1991, p. 91). Since 'mix' is so much a feature of the speech of educated and influential people, it seems likely that, whether it is accepted as a feature of the 'high' variety or not, few users of the high variety manage without it. The colloquial Cantonese is colorful, racy, witty, and rude, with jokes and allusions based on sound similarities and shifts in tone. The media are frequently criticized for popularizing 'low' forms of the language.

Although Johnson recognized the creative and lively aspects of the Cantonese language, he did not problematize the "high" and "low" hierarchy of languages (which has been implicitly defined by political and economic criteria). A linguistic variety is characterized as a "high" variety when it is the language used in government, official, or economic domains. A linguistic variety is characterized as a "low" variety when it is used in everyday, mundane domains. With this saturation of consciousness by implicit value-laden notions even among sociolinguists and educational researchers ${ }^{\text {iv }}$, it is not surprising that many good-intentioned educationists can hold negative views towards Cantonese, the mother tongue of the majority of children and adults in Hong Kong. For example, when listing the sociolinguistic factors that hinder the learning of Chinese in Hong Kong, Law wrote, "Cantonese is a dialect and is constantly vulgarized by comics, TV programmes and films." (Law, 1994, p. 3). We, however, need to worry about the social, psychological, and educational consequences for school children, whose mother tongue, the most important language of their social and cultural identity, is constantly criticized and devalued in the public discourses. The so-called "low" variety of Cantonese, including, for instance, the language and narrative genres used in the Hong Kong versions of 
Japanese comics, which are highly popular among Hong Kong adolescents, represents some of the valuable linguistic, discourse, and cultural resources that Hong Kong children bring with them to the classroom. Any second, foreign, or "standard" language curriculum that aims at affirming and developing the potential, self-confidence, self-identity, and independent thinking ability of children needs to capitalize and build on children's indigenous resources instead of devaluing or marginalizing them (Delpit, 1988; Michaels and Collins, 1984; Tharp and Gallimore, 1988; Au, 1980; Au and Kawakami, 1991). Asserting this does not mean that one should indiscriminately celebrate everything that children bring to the classroom (e.g., sexism, racism, violence). However, if we view education as dialogue between teachers and students and between school culture and children's popular culture (Buber, 1947), and not merely as an authoritative imposition and transmission of a set of adult skills, knowledge, and norms, school education needs to strive to capitalize and build on students' indigenous resources (e.g., their native linguistic and discourse competence) by finding meeting points between children's indigenous culture and school culture (e.g., Jordan, 1985; Lin, 1996).

\section{Employer-Defined Language Goals for Education and Job-Market-Value as the Incentive for Language Learning}

On formulating language goals for the education system in Hong Kong, an important government policy document on language education reads:

\section{Example 9:}

A community-wide effort is needed to clarify what levels of language proficiency are expected by all the main public and private sector organizations in Hong Kong which employ those leaving the education system. This will provide a clearer picture of the language development goals which the education system should seek to achieve. These organizations should identify the patterns of language use in their operations, and define the expected language achievement of their employees. 
(Hong Kong Education Commission, Report of the Working Group on Language Proficiency, July, 1994, pp. 45-46)

A needs-analysis is called for, but it is exclusively an analysis of the needs of the employers, not including the needs of the children, or those of the parents. It is a model of language education in which the goals are defined exclusively by the labor market that is the employers.

Even if one could accept such a labor-producing model of education (and accede to the position that education is not primarily for the development of human potential, or for the social, intellectual and cultural development and enrichment of the human child, but primarily for fulfilling clearly defined, specific labor market needs, as if one was producing specific products for the consumer market, with a concomitant need for a market demand analysis), one would still find such discourses naive and mechanistic. For example, they assume a static labor market; they want to produce labor with exactly those patterns of language skills that the labor market demands at a certain point in time, instead of graduates who are creative, flexible and adaptable language users who can meet the challenges of new and ever-changing work situations. They also seem to have assumed a naive model of language and language learning, i.e., language conceived as separate from culture, social relations, identity, and situated social practice (c.f., Lave and Wenger, 1991), and as isolatable sets of skills and facts that can be clearly defined and imparted to students in the classroom as packets of linguistic knowledge and routine

linguistic operations. Also assumed is a naive model of the social actor. The primary and secondary school child is assumed to be one who will readily be motivated to learn whatever a possible future employer wants her/him to learn, without any regard to her/his current sociocultural and intellectual interests.

\section{An Input/Output Model of Language Learning and a Cognitive Model of the Learner}

The exposure argument is pervasive in all the three kinds of discourses (official, public media, and academic), but especially so in the academic discourses. The single most frequently cited cause of Hong Kong students' poor standards in English (and also Chinese) is their lack of exposure or lack of quality input in English (and in 
proper Chinese) (e.g., Report of the Working Group on Language Proficiency, 1994; Johnson, 1993/1994, 1994). Under this model of language learning, a Hong Kong child is seen as being exposed to far too much Cantonese and far too little Standard Chinese and English. Given so little proper language input, it is natural that the child's language output is poor.

This model of language learning implies an implicit model of the actor as an ahistorical, non-social, non-cultural, cognitive computer. This seems to be the model underlying many current second and foreign language learning and teaching theories. In this model, apart from the affective filter (Krashen, 1982; 1985), an environment offering/requiring maximum comprehensible language input/output is the most important determinant in the language learning process (Krashen, 1982; Swain, 1985).

This model is however relatively silent about what motivates students to learn a second/foreign language. It seems to assume that when immersed in such an environment, students cannot help but learn the language. In this sense, the cognitivism which underlies this model is a form of environmental determinism: by engineering the classroom environment, humans will be led to learn a language $\mathrm{v}$.

This model of language learning is one-sided as it does not take into consideration the fact that language learning and language use involve much more than merely information processing. They involve the transformation of social relations and sociocultural identity (Peirce, 1993, 1995), and the confrontation and interaction of different social and cultural worlds (Kramsch, 1993). However, as shown in the following excerpt from the ECR No. 6, the dominant model underlying official discourses and policies is one of cognitivism, apart from that of commercialism:

\section{Example 10:}

As regards language proficiency, there is no doubt in our mind that this is important on two levels. On the micro level, language proficiency is essential to the cognitive development of a child, 
as it affects his or her ability to assimilate and interpret information. On the macro level, language proficiency is important to maintain Hong Kong's leading position in the financial, commercial and industrial development of China and the Pacific rim.

(Education Commission Report No. 6, December, 1995, Part 1, Chapter 1: Introduction, paragraph 1.2, p. 1)

These public discourses have simplified the Hong Kong child's English learning problem to one consisting of a simple factor: lack of quality exposure. However, lack of exposure is only a superficial characterization of the issue, the core of which has never been touched upon in these exposure arguments. These arguments assume that to help students to learn English, the principal task is to improve the input environment of the students, and to minimize the inappropriate kind of input (i.e., Cantonese). This kind of input/output model treats the human child as an information processing machine without any human agency, and completely ignores the sociocultural, historical, and motivational context of the child, language learning, and language use.

\section{Teachers and Students Seen as Incompetent and Indolent}

The public discourses also often portray teachers and students as sub-standard workers and learners: e.g., the majority of teachers are generally seen as poor in English proficiency and teaching techniques, and characterized as unresponsive to innovative teaching methods, or lacking the energy and commitment to implement new teaching approaches (e.g., Johnson, 1994, p. 31).

Students are characterized as lacking the enterprise to seek out benefit from the foreign language environment in Hong Kong (e.g., Goldstein and Liu, 1994, p. 706), or as being exposed to too much Cantonese popular

culture (e.g., Cantonese pop songs) which has reduced their exposure to English outside school (e.g., Report of the Working Group on Language Proficiency, p. 10). 
The implicit model of the social actor in these discourses seems to be one of an individual whose success or failure in language teaching and learning hinges on her/his ability and/or industry. The sociocultural and historical contexts in which actors (e.g., teachers, students) are always situated and constrained are reduced to an exposure, ability, or industry factor in these discourses. It is implicitly assumed in these discourses that given enough individual enterprise and initiative, anyone can obtain adequate exposure to English which can then lead to success in learning English. If one fails in the language learning or teaching task, it is the individual's lack of ability, initiative, or enterprise that is to be blamed.

\section{Proposing an Alternative Model: Education as Dialogue and Mutual Sociocultural Transformation}

In the above sections I have attempted to expose and problematize the implicit models, values, and ideology of the current public official, media, and academic discourses on the language problem in Hong Kong. I have tried to show how these influential discourses impose a labor-production model of education, denigrate the value of the child's mother tongue, impose a one-sided, cognitive model of language and language learning, assume an ahistorical, non-sociocultural, computer-model of the social actor (e.g., the child, the learner), while at the same time imposing a model of the social actor who is driven by labor-market demands.

With the overwhelmingly one-sided emphasis of the public discourses on the needs of the labor market, and on how the education system can become better able to meet those labor needs, what are left untalked of are the needs of the school, the teacher, and the child. Very often they are on the receiving end of much of the blame for the lamented shortage of English-proficient labor for the labor market. However, what kinds of constraints are they under (e.g., large class size, heavy workload, and lack of staff development opportunities for teachers; a hierarchical school culture that is non-conducive to teacher initiative and autonomy; a top-down approach to the implementation of government educational policies)? What resources do they have and what resources do they not have? Apart from some talk of importing native-English-speaking teachers, the public discourses do not seem to show much interest in these issues. 
We have also seen in the above sections that the labor-market-driven and cognitive models assumed in the public discourses cannot explain why many Hong Kong students are not motivated to learn and use English and Mandarin Chinese (called Standard Chinese in the public discourses). These models ignore the different sociocultural contexts in which different students, teachers, and schools are situated. In doing so, these models also conceal the differential access that students from different socioeconomic and sociocultural backgrounds have to Mandarin Chinese/English linguistic and cultural resources. These models ascribe students' and teachers' lack of English/Mandarin Chinese resources to individual attributes (e.g., lack of competence, industry, initiative). However, they ignore the sociolinguistic reality that Mandarin Chinese/English linguistic and cultural resources are differentially distributed across different social groups in the Hong Kong society, and that different social groups inhabit very different linguistic and sociocultural worlds (for some concrete examples, see Lin, 1996).

The implicit models in the public discourses also assume that a second/foreign/standard language (L2) can be taught through banning the students' indigenous (L1) linguistic and cultural practices from the L2 classroom. In their learning model, immersing a child in an L2 classroom where there is little or no place for her/his L1 practices leads to maximum L2 acquisition. L2 education is not seen as a dialogue between different languages and cultures (Kramsch, 1993), but a one-way immersion and assimilation of the L1 child into the L2 language and culture.

To summarize, the models in these public discourses are untenable for both of their following implicit assumptions:

(i) They assume that all schools in Hong Kong can provide their students with equal access to Mandarin Chinese/English linguistic and cultural resources, ignoring the reality that different schools are situated in different sociocultural worlds with differential access to English/Mandarin Chinese; 
(ii) They assume that a Cantonese child can be motivated to learn Mandarin Chinese/English by immersing her/him in a Mandarin Chinese/English classroom where there is little place for the child's indigenous linguistic and cultural resources.

These untenable models assumed in the public discourses lead us nowhere and seem to only have the effect of scapegoating teachers and students in disadvantaged schools. They will not lead to curricular practices that affirm and capitalize on children's L1 resources to help them to expand their linguistic and sociocultural repertoire to include Mandarin Chinese and English. We need to depart from these models and propose the alternative model of education as dialogue (Buber, 1947) and as interaction of different languages and cultures (Kramsch, 1993). We need to put the child back into the center of our discussion to see what children need (and not merely what the labor market needs) and what kind of language education curriculum can be developed both to meet their intrinsic needs and to equip them with the necessary resources to survive and succeed in, as well as to contribute to, our society.

\section{References}

Au, Kathryn H., 1980. Participation structures in a reading lesson with Hawaiian children: Analysis of a culturally appropriate instructional event. Anthropology and Education Quarterly 11: 91-115. $\mathrm{Au}$, Kath _(. Kawakami, 1991. Culture and ownership: Schooling of minority students. Childhood Education 67(5): 280-284.

Bourdieu, Piere, 1982/1991. Language and symbolic power (G. Raymond and M. Adamson, Trans.). Cambridge, Mass.: Cambridge University Press. (Original work published 1982)

Buber, Martin, 1947. Between man and man. London: Routledge and Kegan Paul Ltd.

Chow, Lotte, 1995. Drop in English standard hurts Hong Kong business. Asian Wall Street Journal Weekly, June 12: 1-2.

Delpit, Lisa D., 1988. The silenced dialogue: Power and pedagogy in educating other people's children. Harvard Educational Review 58(3): 280-298. 
Fu, Gail S., 1987. The Hong Kong Bilingual. In: R. Lord and H. N. L. Cheng, Eds., Language education in Hong Kong, 27-50. Hong Kong: Chinese University Press.

Goldstein, Lawrence and Ngar-Fun Liu, 1994. An integrated approach to the design of an immersion program. TESOL Quarterly 28(4): 705-725.

Hong Kong Education Commission, 1990. Education Commission report (4). Hong Kong: Education Commission.

Hong Kong Education Commission, 1994. Report of the working group on language proficiency. Hong Kong: Education Commission.

Hong Kong Education Commission, 1995. Education Commission report (6). Education Commission. Johnson, Robert K., 1993/1994. Language policy and planning in Hong Kong. Annual Review of Applied Linguistics 14: 177-199.

Johnson, Robert K. 1994. Critical review of literature on language in education in Hong Kong. Report prepared for the Hong Kong Education Commission Working Group on Language Proficiency.

Jordan, Cathie, 1985. Translating culture: From ethnographic information to educational program. Anthropology and Education Quarterly 16(2): 105-123.

Kramsch, Claire, 1993. Context and culture in language teaching. Oxford: Oxford University Press.

Krashen, Stephen, 1982. Principles and practice in second language acquisition. Oxford: Pergamon.

Krashen, Stephen, 1985. The input hypothesis: Issues and Implications. New York: Longman.

Lave, Jean and Evelyn Wenger, 1991. Situated learning: Legitimate peripheral participation. Cambridge: Cambridge University Press.

Law, Eva, 1994. Recommendations for improvement in language proficiency. Report submitted to the Hong Kong Education Commission Working Group on Language Proficiency.

Li, Kui-Wah, and Lo, Kenneth W-K., 1994. Trade and industry. In: P-K. Choi and L-S. Ho, Eds., The other Hong Kong report: 1993, 109-126. Hong Kong: Chinese University Press.

Lin, Angel M. Y., 1996. Doing-English-lessons in secondary schools in Hong Kong: A sociocultural and discourse analytic study. Unpublished doctoral dissertation, University of Toronto, Canada. 
Luke, Kang-Kwong, 1984. Expedient and orientational language mixing in Hong Kong. York Papers in Linguistics 11: 191-201.

Luke, Kang-Kwong and Owen T. Nancarrow, 1991. On being literate in Hong Kong. Institute of Language in Education Journal 8: 84-92.

Luke, Kang-Kwong and Jack C. Richards, 1982. English in Hong Kong: Functions and status. English World-Wide $\underline{3}$ (1): 47-64.

Ma, Shu-Yan, 1995. The Renminbi threat to Hong Kong's dollar. Asian Wall Street Journal, March 9.

Michaels, Sarah, and James Collins, 1984. Oral discourse styles: Classroom interaction and the acquisition of literacy. In: D. Tannen, Ed., Coherence in spoken and written discourse, 219-244. Norwood, N.J.: Ablex.

Pease, Robert M., 1994. Mandarin may become Asia's language of commerce. Asian Wall Street Journal Weekly, September 19, 1994, p. 12.

Peirce, Bonny N., 1993. Language learning, social identity, and immigrant women. Unpublished doctoral dissertation, University of Toronto, Canada.

Peirce, Bonny N., 1995. Social identity, investment, and language learning. TESOL Quarterly 29(1): 9-31. Schumann, John, 1976. Social distance as a factor in second language acquisition. Language Learning $\underline{26}$ : $135-143$.

South China Morning Post, April 28, 1994. Our second language (Editorial).

South China Morning Post, May 24, 1994. Exam results show English skills in decline.

Swain, Merrill, 1985. Communicative competence: some roles of comprehensible input and comprehensible output in its development. In: S. Gass and C. Madden, Eds., Input in second language acquisition, 235-253. Rowley, Mass.: Newbury House.

Tharp, Roland G. and Ronald Gallimore, 1988. Rousing minds to life: Teaching, learning, and schooling in social context. Cambridge: Cambridge University Press.

Notes 
${ }^{\mathrm{i}}$. The Education Commission is a special commission appointed by the Hong Kong Government "(a) to define overall educational objectives, formulate educational policy, and recommend priorities for implementation having regard to resources available; (b) to co-ordinate and monitor the planning and development of education at all levels; and (c) to initiatey educational research" (Hong Kong Education Commission, 1990).

ii . A note of caution to the Hong Kong reader is needed here: as someone having grown up in Hong Kong, I have found it emotionally unsettling to critically reflect on many taken-for-granted notions. This, however, only testifies to the saturation of consciousness by popular, unexamined notions and the need to place them under a critical lens to examine their implicit precepts, which have prevented us from conceiving of any educational models, policies or practices other than those asserted by the public discourses.

iii. There has also been the intimidating argument that if Hong Kong schools do not produce more English-conversant graduates, foreign business corporations will do business directly with China instead of through Hong Kong. This argument is also one-sided for it neglects other equally or more important factors: the linguistic factor is only one among the many other important factors that have attracted foreign businesses to Hong Kong, e.g., a relatively efficient and corruption-free administrative environment, a relatively politically stable environment, well-established commercial, managerial systems and practices, Hong Kong business people's familiarity with Chinese culture and administrative practices, an efficient transport network, well-developed communications systems, an efficient and open financial market, etc., (Li and Lo, 1994).

iv . It must be pointed out that local sociolinguists and educationists do not coin the terms "high" or "low" themselves but are merely drawing on conventional sociolinguistic terminology. While sociolinguists generally do not take these terms as having any pejorative meanings, many of the terms have over the years acquired negative connotations in the public domain. My critique is, therefore, not of the 
sociolinguists or educationists themselves but of the general lack of problematization of these terms in the literature.

${ }^{\mathrm{v}}$. Krashen $(1982,1985)$ also talks about the affective filter of the learner which can filter out the input. Other second language acquisition (SLA) researchers have also theorized and researched on the nature of SLA motivation, e.g., Schumann, 1976 (but see critique of Schumann by Peirce, 1993, 1995). The public discourses in Hong Kong, however, tend to focus primarily on one aspect of second language learning--exposure. 